\title{
DÜBLIN
}

Technological University Dublin

ARROW@TU Dublin

\section{Quantification of trace metals in infant formula premixes using laser-induced breakdown spectroscopy}

\author{
Raquel Cama-Moncunill \\ Technological University Dublin, raquel.cama@tudublin.ie \\ Maria Piedad Casado-Gavalda \\ Technological University Dublin, maria.casado@tudublin.ie \\ Xavier Cama-Moncunill \\ Technological University Dublin
}

See next page for additional authors

Follow this and additional works at: https://arrow.tudublin.ie/schfsehart

Part of the Chemistry Commons, Food Science Commons, and the Medical Sciences Commons

\section{Recommended Citation \\ Raquel Cama-Moncunill, Maria P. Casado-Gavalda, Xavier Cama-Moncunill, Maria Markiewicz-Keszycka, Yash Dixit, Patrick J. Cullen, Carl Sullivan, Quantification of trace metals in infant formula premixes using laser-induced breakdown spectroscopy, Spectrochimica Acta Part B: Atomic Spectroscopy, Volume 135, 2017, Pages 6-14, ISSN 0584-8547, DOI: 10.1016/j.sab.2017.06.014.}

This Article is brought to you for free and open access by the School of Food Science and Environmental Health at ARROW@TU Dublin. It has been accepted for inclusion in Articles by an authorized administrator of ARROW@TU Dublin. For more information, please contact arrow.admin@tudublin.ie, aisling.coyne@tudublin.ie, gerard.connolly@tudublin.ie.

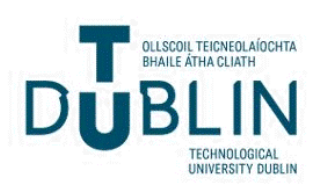




\section{Authors}

Raquel Cama-Moncunill, Maria Piedad Casado-Gavalda, Xavier Cama-Moncunill, Maria MarkiewiczKeszycka, Yash Dixit, Patrick J. Cullen, and Carl Sullivan 


\title{
Quantification of trace metals in infant formula premixes using laser-induced breakdown spectroscopy
}

\author{
Raquel Cama-Moncunill a,*, Maria P. Casado-Gavalda ${ }^{\text {a }}$, Xavier Cama-Moncunill a , Maria Markiewicz-Keszycka a , \\ Yash Dixit $^{\mathrm{a}}$, Patrick J. Cullen ${ }^{\mathrm{a}, \mathrm{b}}$, Carl Sullivan ${ }^{\mathrm{a}}$ \\ a School of Food Science and Environmental Health - Dublin Institute of Technology, Cathal Brugha St, Dublin 1, Ireland \\ b School of Chemical Engineering, UNSW Australia, Sydney, NSW 2052, Australia
}

\section{A R T I C L E I N F O}

\section{Article history:}

Received 22 February 2017

Received in revised form 24 May 2017

Accepted 23 June 2017

Available online 24 June 2017

\section{Keywords:}

LIBS

Trace-element premixes

Univariate analysis

Multivariate analysis

PLS

\begin{abstract}
A B S T R A C T
Infant formula is a human milk substitute generally based upon fortified cow milk components. In order to mimic the composition of breast milk, trace elements such as copper, iron and zinc are usually added in a single operation using a premix. The correct addition of premixes must be verified to ensure that the target levels in infant formulae are achieved. In this study, a laser-induced breakdown spectroscopy (LIBS) system was assessed as a fast validation tool for trace element premixes. LIBS is a promising emission spectroscopic technique for elemental analysis, which offers real-time analyses, little to no sample preparation and ease of use. LIBS was employed for copper and iron determinations of premix samples ranging approximately from 0 to $120 \mathrm{mg} / \mathrm{kg} \mathrm{Cu} /$ $1640 \mathrm{mg} / \mathrm{kg}$ Fe. LIBS spectra are affected by several parameters, hindering subsequent quantitative analyses. This work aimed at testing three matrix-matched calibration approaches (simple-linear regression, multi-linear regression and partial least squares regression (PLS)) as means for precision and accuracy enhancement of LIBS quantitative analysis. All calibration models were first developed using a training set and then validated with an independent test set. PLS yielded the best results. For instance, the PLS model for copper provided a coefficient of determination $\left(R^{2}\right)$ of 0.995 and a root mean square error of prediction (RMSEP) of $14 \mathrm{mg} / \mathrm{kg}$. Furthermore, LIBS was employed to penetrate through the samples by repetitively measuring the same spot. Consequently, LIBS spectra can be obtained as a function of sample layers. This information was used to explore whether measuring deeper into the sample could reduce possible surface-contaminant effects and provide better quantifications.
\end{abstract}

(c) 2017 Elsevier B.V. All rights reserved.

\section{Introduction}

Infancy is an important period of development, in which an adequate nutrition is essential for the growth of a healthy child. Infant formula is a human milk substitute, typically commercialized in powder form, which is generally made from cow milk with the addition of lactose, whey protein, vegetable oils, minerals and vitamins [1,2]. Minerals and vitamins are usually added using a premix [3]. Premixes are blends, typically added prior to spray-drying, which are designed to contain specified nutrients in a predetermined and fixed ratio [3,4]. Trace elements ( $\mathrm{Fe}, \mathrm{Cu}, \mathrm{Zn}, \mathrm{Se}, \mathrm{Mn}$ and I) are present in $\mu \mathrm{g}$ or lower concentrations per $100 \mathrm{kcal}^{-1}$ and are normally incorporated via blending with a single premix $[1,4]$.

Infant formulae face strict quality controls. The composition of each batch or in-process batch must be verified before packaging; as well as ingredients, including premixes, produced by the manufacturer or without a supplier's certificate $[5,6]$. To guarantee correct addition and

\footnotetext{
* Corresponding author.

E-mail address: d13125826@mydit.ie (R. Cama-Moncunill).
}

uniform distribution of premixes, manufacturers may determine the levels of indicator nutrients (e.g. iron) in-process or at the final product assessment $[7,8]$. The Codex Alimentarius establishes minimum levels for trace elements: iron $(0.45 \mathrm{mg} / 100 \mathrm{kcal})$, zinc $(0.5 \mathrm{mg} / 100 \mathrm{kcal})$ and copper $(35 \mu \mathrm{g} / 100 \mathrm{kcal})$. While no maximum limits are provided, guided upper levels are indicated for zinc $(1.5 \mathrm{mg} / 100 \mathrm{kcal})$ and copper $(120 \mu \mathrm{g} / 100 \mathrm{kcal})$ [9]. Iron, zinc and copper determinations in infant formula are traditionally conducted by atomic absorption spectrometry (AAS) following the AOAC 985.35 [10].

Invented in the 1960s, laser-induced breakdown spectroscopy (LIBS) is a growing and promising technique for elemental analysis [11]. LIBS is an atomic emission spectroscopic technique which uses highly energetic laser pulses as an excitation source. The interaction between laser pulses and the sample gives rise to material ablation and subsequent hot-plasma formation [12,13]. This plasma is composed of excited ionic and atomic species-and in some cases molecular species [14] -which emit radiation as the plasma cools down and the species return to their fundamental state [12]. These emissions are characteristic of the atoms and ions present in the plasma, known as characteristic spectral emission lines of the elements, and constitute the signal/ 
spectrum recorded in LIBS $[12,13]$. LIBS provides a number of advantages over traditional methods such as fast analysis, minimal sample preparation, multi-element capability, ease of use and no need of chemical reagents [15-17]. This features make LIBS adequate for in- and online applications [18].

During the last decades, LIBS has seen its use in several fields $[19,20]$. Yet, in food applications, the technology is still in its early days [21]. LIBS has demonstrated its ability for qualitative analysis of milk and infant formula powders [22]. However, performing quantitative analysis is not straight forward. In LIBS, element emission responses are influenced by the analyte-matrix combination and the environment, affecting the precision and accuracy of the measurements [12,14,23-25]. Since food samples are rather complex and heterogeneous, matrix effects may play an important role. Accurate and precise determination of food elements still remains an important challenge. To overcome these drawbacks of LIBS, some quantification approaches such as univariate analysis, multivariate analysis and calibration-free methods have been employed [25]. A calibration-free approach was applied for the determination of several mineral elements in milk powders [26]. Current trends in LIBS quantification include building calibration methods from matrix-matched reference standards, especially via chemometric/multivariate analysis [20] since they are less affected by fractionation issues (non-stoichiometric ablation) [27] and have been reported to reduce such matrix effects [28]. LIBS combined with multivariate analysis was used to determine whey adulterations in milk powders [29]. More recently, LIBS has demonstrated its ability to determine major minerals such as Ca in milk powders [30] and infant formulas [31]. LIBS is essentially a surface analysis technique; therefore, the surface condition of the samples may have an impact on the measurements [28]. However, repetitive sampling at the same location can be used to penetrate through the surface layer, providing information on bulk composition and homogeneity. Additionally, this information could be used to explore whether more accurate quantifications can be obtained from the analysis of the inner-sample-layer spectra. Performing conditioning shots could help deal with possible surface contaminants such as Na.

This work aims to assess the ability of a LIBS system to determine trace-elements of copper and iron within premix samples varying in proportion blends between pure premix to pure lactose. As mention before, quantitative analyses of LIBS are complex and subsequently require methodological approaches to reduce matrix effects, and improve precision and accuracy. In this study, three methodologies based on matrix-matched calibration have been appraised: univariate analysis, multi-linear regression and partial least squares regression. The selection of analytical characteristic emission lines for model development is discussed, along with the effect of considering emission lines not directly related to the analyte emission. Furthermore, measuring deeper into the sample was explored as a means to avoid influences from possible surface contaminants. LIBS holds great potential as an at-line validation tool for infant formula manufacture. An optimized LIBS quantitative approach would provide fast elemental analyses of premixes, providing the means to rapidly verify that target concentrations of premixes added to infant formula are achieved.

\section{Material and methods}

\subsection{Sample preparation}

A trace-mineral premix containing $1640 \mathrm{mg} / \mathrm{kg}$ of Fe and $120 \mathrm{mg} / \mathrm{kg}$ of $\mathrm{Cu}$ was acquired from Vitablend (Netherlands) and lactose ( $\alpha$-lactose monohydrate $\geq 99 \%$ ) was purchased from Sigma Aldrich (Ireland). Apart from iron and copper, the premix also contained other trace minerals as all these nutrients are usually added together in a single operation [4]. The amounts of each nutrient in the premix kept the same inter-element ratios as in infant formulae. Similar to industrial premixes, iron and copper were incorporated in sulphate form $\left(\mathrm{FeSO}_{4}\right.$ and $\left.\mathrm{CuSO}_{4}\right)$ with lactose used as the carrier [1]. The complete composition of the premix is shown in Table S1.

In order to assess a range of trace-element concentrations, a series of mixtures with varying proportion of lactose and premix were prepared. Blend concentrations of the premix and lactose were calculated on the basis of the following target copper levels: $0,5,10,20,40,60,80,100$ and $120 \mathrm{mg} / \mathrm{kg}$; whose iron levels were then approx. 0, 68, 137, 273, $547,820,1093,1367$ and $1640 \mathrm{mg} / \mathrm{kg}$, respectively. For all mixtures, a final weight of $100 \mathrm{~g}$ was prepared via dry-blending using a laboratory V-mixer (FTLMV-1L\&, Filtra Vibracion S.L., Spain). Three independent batches of mixtures containing each of the nine $\mathrm{Cu}$ and Fe levels were prepared (27 samples in total). For LIBS analysis, 3 pellets were made from each sample ( 81 pellets in total). The pellets were manufactured using a single die manual hydraulic press (Specac Ltd., UK) in which approx. $400 \mathrm{mg}$ were pressed at 10 tons for $3 \mathrm{~min}$.

\subsection{Atomic absorption spectrometry}

Iron and copper determinations were conducted via atomic absorption spectrometry (AAS). Since iron levels ranged from approx. 1 to $1600 \mathrm{mg} / \mathrm{kg}$, determination were carried out with flame AAS (FAAS) (Varian 55B AA, Agilent Technologies, USA). Copper contents (approx. from 1 to $120 \mathrm{mg} / \mathrm{kg}$ ) were determined with graphite furnace AAS (GFAAS) using the Zeeman option (Varian AA240Z and AA280Z Zeeman, Agilent Technologies, USA) as Flame AAS was not sensitive enough to quantify the lower $\mathrm{Cu}$ levels. Both AAS methods are based on building a calibration curve from standard solutions of the desired element. Copper (cat. no. 38996) and iron (cat. no. 16596) standard solutions were purchased from Sigma Aldrich (Ireland). As similar sample preparations were required, the same sample aliquots were used for both determinations. Analyses were conducted according to the standard method of the AOAC (1998) for mineral determination in infant formula (method 985.35) with some variations. Approx. $1.5 \mathrm{~g}$ of the premix sample, previously dried in an oven at $102{ }^{\circ} \mathrm{C}$ for approx. $16 \mathrm{~h}$, were transferred to a crucible in triplicates, providing a total of 81 aliquots ( 3 batches $* 9$ conc $* 3$ replicates). The crucibles were covered with lids since lactose is liable to overflow or cause partial sample ejection when heated. To facilitate digestion, samples were pre-ashed on a hot plate with correct $1 \mathrm{ml}$ of purified nitric acid (CAS 7697-37-2, Sigma Aldrich) until blackened. Samples were placed in a muffle furnace at $525{ }^{\circ} \mathrm{C}$ until grey/white ashes were obtained (approx. $3 \mathrm{~h}$ ). Nitric acid $1 \mathrm{~mol} / \mathrm{l}$ was used to rinse the lids and crucibles and dissolve the ashes into $25 \mathrm{ml}$ volumetric flasks. From these solutions, two further dilutions in parallel, one for copper and the other for iron, were performed in order to bring both element concentrations within the FAAS ( 1 to $15 \mathrm{mg} / \mathrm{kg} \mathrm{Fe}$ ) and GFAAS $(0-30 \mu \mathrm{g} / \mathrm{kg} \mathrm{Cu})$ optimum measuring ranges. All AAS analyses were conducted in triplicates. Results were calculated as $\mathrm{mg} / \mathrm{kg}$ of copper and iron of dried matter (DM).

\subsection{LIBS instrumentation and measurements}

LIBS spectral data was obtained with a LIBSCAN-150 system (Applied Photonics Limited, UK), which comprises of a Q-switched $\mathrm{Nd}$ :YAG laser operating at $1064 \mathrm{~nm}$ with a pulse energy of $150 \mathrm{~mJ}$, repetition rate of $1 \mathrm{~Hz}$ and pulse duration of $5 \mathrm{~ns}$; coupled with a six-spectrophotometer array (AvaSpec Avantes spectrometers, Netherlands) covering the wavelength range from 185 to $904 \mathrm{~nm}$. Plasma emission was recorded at $1.27 \mu$ s delay time with an integration time of $1.1 \mathrm{~ms}$. Pellets were measured individually in a sample chamber equipped with an XYZ translation stage (Applied Photonics Limited, UK) which facilitates multiple-point data acquisition. The optimum focal distance was approx. $84 \mathrm{~mm}$ from the laser aperture. Spectral acquisition of a single pellet consisted of the consecutive recording of 5 spectra at the same spot from 100 different locations following a $10 \times 10$ grid pattern with an inter-spot distance of $0.85 \mathrm{~mm}$. From a spatial point of view, the set of data points can be seen as cube of 5 layers and a base of $10 \times 10$ 
locations (500 spectra per pellet in total). Measurements were performed with neither conditioning shots nor accumulations and the three independent batches were analysed on different days. The approximate measuring time per sample was almost $9 \mathrm{~min}$. The spectral acquisition and $\mathrm{x}-\mathrm{y}-\mathrm{z}$ translation of the stage were controlled through LIBsoft software (Applied Photonics Limited, UK).

\subsection{LIBS quantitative analysis}

Spectral pre-processing and data analysis were performed in $\mathrm{R}(\mathrm{R}$ Core Team, 2014) with the use of R commands and packages, including; baseline, stats and pls, as well as other in-house functions.

Data pre-processing is usually performed prior to model development in order to remove extraneous signal variations [32] introduced by fluctuations in experimental conditions and matrix effects [33]. The background signal can be removed from LIBS spectra using a baseline correction algorithm [34]. To this end, the Iterative Restricted Least Squares (IRLS) algorithm included in R [35] was applied to the raw spectra. Additional pre-processing was explored, however the approach proved detrimental to the model's performance. The baseline corrected spectra were averaged to obtain a single spectra per sample/pellet (100 locations $* 5$ layers) and also per each of the 5 layers/depths (100 locations). The former were used to develop models with several quantitative approaches, while the latter was used to explore whether measuring deeper into the sample could help deal with possible surface contamination.

LIBS quantitative analyses were conducted by means of univariate and multivariate analysis. Respective matrix-matched calibration models were developed from the correlation of LIBS data, after baseline removal and averaging per sample, to the variation of copper and iron, separately. Spectral data, along with the respective reference values, was equally divided into training and test sets for all the calibration approaches. The training set consisted of two independent sample batches $(N=54)$; while the test set comprised a third independent batch $(N=$ 27).

\subsubsection{Univariate analysis}

Univariate analysis or simple linear regression (SLM) is the simplest approach for predicting a quantitative response $Y$ (e.g. copper content) from a single predictor variable $X$ (e.g. intensity at a copper line) by assuming that there is a linear relationship between $X$ and $Y$ [36]. Two simple linear models were built, one for copper and one for iron, by correlating the intensity of the most prominent $\mathrm{Cu}$ or Fe emission line to the reference values. The copper curve used the peak intensity at $324.754 \mathrm{~nm}$, which corresponds to a $\mathrm{Cu}^{\mathrm{I}}$ persistent line; while the iron model used the signal at $438.36 \mathrm{~nm}$ which is associated with a $\mathrm{Fe}^{\mathrm{I}}$ persistent line [37]. Model evaluation was carried out through the figures of merit detailed in Section 2.4.3. Additionally, the limit of detection (LOD) was calculated according to Eq. (1) [38]:

$L O D=\frac{3 \times S D_{\text {blank }}}{S}$

where $S D_{\text {blank }}$ is the standard deviation of the blank samples and $s$ is the slope of the calibration curve.

\subsubsection{Multivariate analysis}

In contrast to univariate analysis, multivariate calibration takes into account several predictor variables $X$ (spectral responses) measured from a number of samples to predict the quantitative response $Y$ (e.g. copper concentration) [39]. Two multivariate analysis approaches were used: multi-linear regression (MLR) and partial least squares regression (PLS).

MLR models for copper and iron were built by correlating the signal from various $\mathrm{Cu}$ and Fe emission lines respectively to their reference values. The most prominent emission lines, in which the intensity increased with the analyte-concentration, were chosen as the predictor variables. The copper model comprised two $\mathrm{Cu}^{\mathrm{I}}$ lines (324.7 and $327.4 \mathrm{~nm})$; while the iron model used $\mathrm{Fe}^{\mathrm{I}}(438.36 \mathrm{~nm}), \mathrm{Fe}^{\mathrm{II}}$ (259.95 nm), Fe $(358.119 \mathrm{~nm}), \mathrm{Fe}^{\mathrm{I}}$ (373.486 nm), Fe $\mathrm{I}^{\mathrm{I}}(430.79 \mathrm{~nm})$ and $\mathrm{Fe}^{\mathrm{I}}(432.576 \mathrm{~nm})$. Model assessment was performed in the same fashion as for the univariate analysis.

PLS is a widely employed multivariate analysis technique [40] where the calibration models are developed from linear combinations of the predictor variable, rather than the original variables [39]. These predictor variables, known as factors or components, are selected so that they are highly correlated with the response variable and also explain the variation in the predictor variables [39]. The full LIBS spectra were correlated to the variation of copper and iron, separately, by means of PLS. Both $\mathrm{Cu}$ and Fe calibrations were built using the training data set. Additionally, cross-validation using the leave-one-out (LOO) method was conducted as it provides guidance on the optimal number of factors to include in the calibration model, preventing possible overfitting issues [41]. Parameters such as the determination coefficient of cross-validation $\left(R^{2}{ }_{c v}\right)$ and root mean square error of cross-validation (RMSECV) were also considered for model assessing. Furthermore, PLS was similarly applied on the five data sets obtained from averaging the spectra per sample layer/depth, providing five additional calibrations per element.

For the multivariate calibration models, the pseudounivariate LOD $\left(\right.$ LOD $\left._{\mathrm{pu}}\right)$ proposed by the IUPAC was calculated according to Eq. (2) $[42,43]$ :

$L O D_{p u}=3.3 s_{p u}^{-1}\left[\left(1+h_{0 \min }+1 / I\right) \quad v a r_{p u}\right]^{1 / 2}$

where $s_{p u}^{-1}$ is the slope of the pseudounivariate line, $h_{0 \min }$ is the minimum leverage when analyte concentration is zero, and $\operatorname{var}_{p u}$ is the variance of the regression residuals.

\subsubsection{Assessment of the calibration approaches}

In order to provide comparisons, several figures of merit were estimated for all the calibration approaches. The parameters used for assessing the calibration performances were the coefficients of determination $\left(R^{2}\right)$ and root mean square error of calibration (RMSEC) computed from the correlations of the training set to the element variation. Once the calibration models were fitted, they were tested to predict the copper and iron concentrations from an independent sample set (test set). The predictive ability was then appraised by the root mean square error of prediction (RMSEP) and the determination coefficient $\left(R_{p}^{2}\right)$ generated with the fitted values from the test set.

\section{Results and discussion}

\subsection{Atomic absorption spectrometry}

GFAAS and FAAS were conducted as reference methods for copper and iron determinations of the premix samples, respectively. Both techniques require building a calibration curve from the reference standard solutions, whose performance will determine the accuracy of the results. Good calibration curves with high coefficients of determination were obtained for both elements: copper by GFAAS $\left(R^{2} \geq 0.992\right)$ and iron by FAAS $\left(R^{2} \geq 0.998\right)$. The results, expressed as $\mathrm{mg} / \mathrm{kg}$ in dry matter, are shown in Table 1.

\subsection{LIBS spectral features}

Exploratory analysis of various spectra was performed in order to identify the main element emission lines as well as determine the major spectral differences among the samples studied, with particular regard to copper and iron characteristic lines. Fig. 1 shows the full LIBS spectra baseline corrected and averaged to a single spectrum per sample (including the 5 depths) of pure lactose, premix-lactose mixture at $50 \%$ 
Table 1

Copper and iron contents in dry matter (DM) of the lactose-premix samples determined by GFAAS and FAAS, respectively.

\begin{tabular}{|c|c|c|c|}
\hline Batch & Sample & Cu content $(\mathrm{mg} / \mathrm{kg} \mathrm{DM})^{\mathrm{a}}$ & Fe content $(\mathrm{mg} / \mathrm{kg} \mathrm{DM})^{\mathrm{a}}$ \\
\hline 0 & Lactose & $0.9 \pm 0.2$ & $1.0 \pm 0.257$ \\
\hline \multirow[t]{8}{*}{1} & Premix 5 & $4.79 \pm 0.22$ & $63.83 \pm 2.30$ \\
\hline & Premix 10 & $9.29 \pm 0.36$ & $132.69 \pm 3.40$ \\
\hline & Premix 20 & $19.50 \pm 1.84$ & $278.50 \pm 9.07$ \\
\hline & Premix 40 & $35.99 \pm 0.53$ & $524.15 \pm 18.02$ \\
\hline & Premix 60 & $58.10 \pm 3.91$ & $797.68 \pm 10.84$ \\
\hline & Premix 80 & $74.11 \pm 4.29$ & $1045.41 \pm 35.59$ \\
\hline & Premix 100 & $86.46 \pm 23.83$ & $1283.32 \pm 45.26$ \\
\hline & Premix 120 & $108.76 \pm 3.79$ & $1537.55 \pm 71.89$ \\
\hline \multirow[t]{8}{*}{2} & Premix 5 & $5.44 \pm 0.11$ & $65.44 \pm 0.92$ \\
\hline & Premix 10 & $12.03 \pm 0.24$ & $158.70 \pm 3.27$ \\
\hline & Premix 20 & $22.19 \pm 1.26$ & $279.67 \pm 6.97$ \\
\hline & Premix 40 & $41.49 \pm 0.37$ & $542.43 \pm 3.75$ \\
\hline & Premix 60 & $62.68 \pm 3.03$ & $803.77 \pm 19.95$ \\
\hline & Premix 80 & $79.38 \pm 1.59$ & $1074.54 \pm 19.58$ \\
\hline & Premix 100 & $99.43 \pm 4.95$ & $1358.60 \pm 29.69$ \\
\hline & Premix 120 & $118.30 \pm 3.52$ & $1615.19 \pm 42.90$ \\
\hline \multirow[t]{8}{*}{3} & Premix 5 & $5.08 \pm 0.15$ & $63.51 \pm 4.24$ \\
\hline & Premix 10 & $10.74 \pm 0.24$ & $130.72 \pm 5.01$ \\
\hline & Premix 20 & $21.72 \pm 0.23$ & $261.18 \pm 1.57$ \\
\hline & Premix 40 & $41.71 \pm 0.32$ & $520.22 \pm 5.27$ \\
\hline & Premix 60 & $61.02 \pm 1.84$ & $769.19 \pm 10.05$ \\
\hline & Premix 80 & $85.52 \pm 1.70$ & $1065.62 \pm 28.60$ \\
\hline & Premix 100 & $104.22 \pm 5.60$ & $1272.54 \pm 45.85$ \\
\hline & Premix 120 & $115.15 \pm 7.27$ & $1543.16 \pm 108.81$ \\
\hline
\end{tabular}

a Contents expressed as mean \pm standard deviation of three replicates.

(approx. $60 \mathrm{mg} / \mathrm{kg} \mathrm{Cu}$ and $820 \mathrm{mg} / \mathrm{kg} \mathrm{Fe}$ ) and pure premix (approx. $120 \mathrm{mg} / \mathrm{kg} \mathrm{Cu}$ and $1640 \mathrm{mg} / \mathrm{kg} \mathrm{Fe}$ ). A series of characteristic emission lines can be observed in all three spectra. With reference to the NIST [37] database, these lines were identified as $\mathrm{C}^{\mathrm{I}}(247.8 \mathrm{~nm}), \mathrm{Ca}^{\mathrm{I}}(422.7$ and $616.2 \mathrm{~nm}), \mathrm{Ca}^{\mathrm{II}}(393.3 \mathrm{~nm}), \mathrm{Na} \mathrm{I}(589 \mathrm{~nm}), \mathrm{H}^{\mathrm{I}}(656.3 \mathrm{~nm}), \mathrm{N}^{\mathrm{I}}$ (746.9, 818.5, 821.6 and $868 \mathrm{~nm}), \mathrm{K}^{\mathrm{I}}$ (766.5), $\mathrm{O}^{\mathrm{I}}$ (777.2 and $\left.844.6 \mathrm{~nm}\right)$. Additionally, all three spectra included the molecular emission band of
$\mathrm{CN}$ (from 385.03 to $388.31 \mathrm{~nm}$ ). Detection of $\mathrm{C}, \mathrm{H}$ and $\mathrm{O}$ was expected since these elements constitute the lactose molecule. Yet, high intensities observed at the $\mathrm{O}$ lines together with the $\mathrm{N}$ signal indicated atmospheric contributions [44]. Na, Ca and $\mathrm{K}$ detections were also expected as these alkali and alkaline earth metals are typically present in dairy derivates and are easily detected by LIBS. However, high intensities may indicate surface contamination as these elements are naturally present in most environments. Unlike the lactose spectrum, premix spectra (Fig. 1(b) and (c)) clearly revealed a series of lines from the emission of copper, iron and zinc. Copper's most prominent emission lines were observed at 324.7 and $327.4 \mathrm{~nm}$, while iron emitted at $259.95 \mathrm{~nm}\left(\mathrm{Fe}^{\mathrm{II}}\right)$ and $438.4 \mathrm{~nm}\left(\mathrm{Fe}^{\mathrm{I}}\right)$ [37]. Fig. 2 displays a closer view of all LIBS spectra at (a) $\mathrm{Cu}^{\mathrm{I}} 324.7 \mathrm{~nm}$ and (b) Fe $259.95 \mathrm{~nm}$. In general, higher intensities were observed with increases in $\mathrm{Cu}$ and $\mathrm{Fe}$ concentrations.

\subsection{Calibration models}

Quantitative analysis of LIBS is not straightforward and requires an adequate calibration strategy [25]. Matrix-matched calibration approaches, where standards and unknown sample have the same bulk composition, can provide better results as factors such as matrix effects are minimized [25,28]. In this section, univariate analysis (SLR) and multivariate analysis (MLR and PLS) approaches were tested and compared as calibration methodologies for LIBS quantitative analysis.

\subsubsection{Simple-linear regression (SLM)}

Calibration curves were developed by correlating the peak intensity of the characteristic lines $\mathrm{Cu}^{\mathrm{I}}(324.75 \mathrm{~nm})$ and $\mathrm{Fe}^{\mathrm{I}}(438.36 \mathrm{~nm})$ respectively to the copper and iron values determined by AAS. The $R^{2}$ values were 0.85 for copper and 0.88 for iron, indicating a notable linear relationship between the element concentration and the emission signal. Additionally, the low RMSEC values ( $15 \mathrm{mg} / \mathrm{kg} \mathrm{Cu}$ and $186 \mathrm{mg} / \mathrm{kg} \mathrm{Fe}$ ) demonstrated reasonable accuracy in the frame of calibration. The predictive ability of the models was evaluated by testing the models against

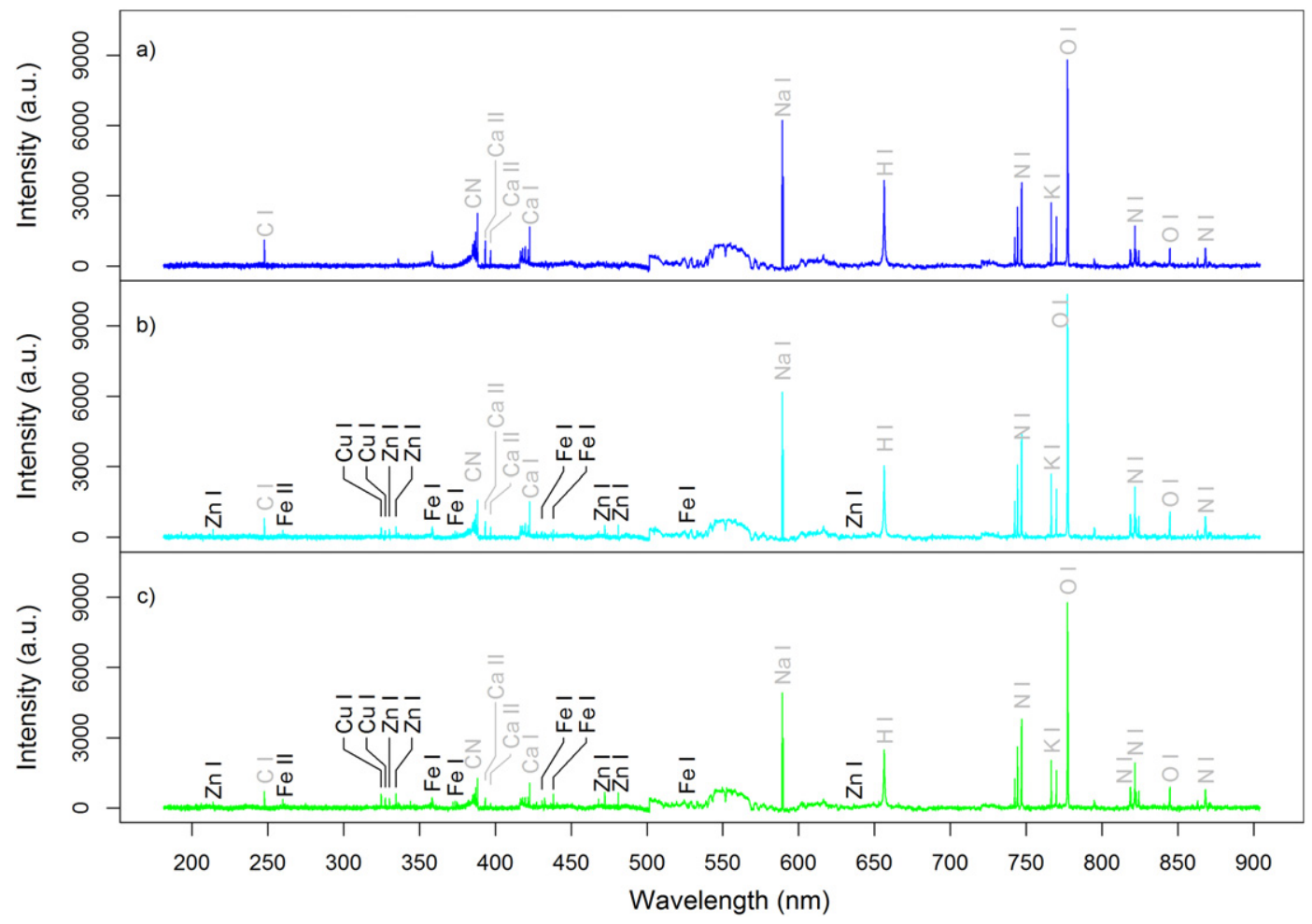

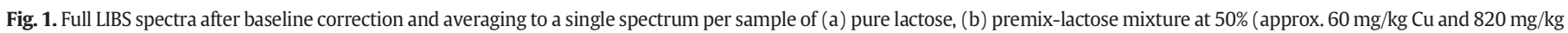
$\mathrm{Fe}$ ) and (c) pure premix (approx. $120 \mathrm{mg} / \mathrm{kg} \mathrm{Cu}$ and $1640 \mathrm{mg} / \mathrm{kg} \mathrm{Fe}$ ). 

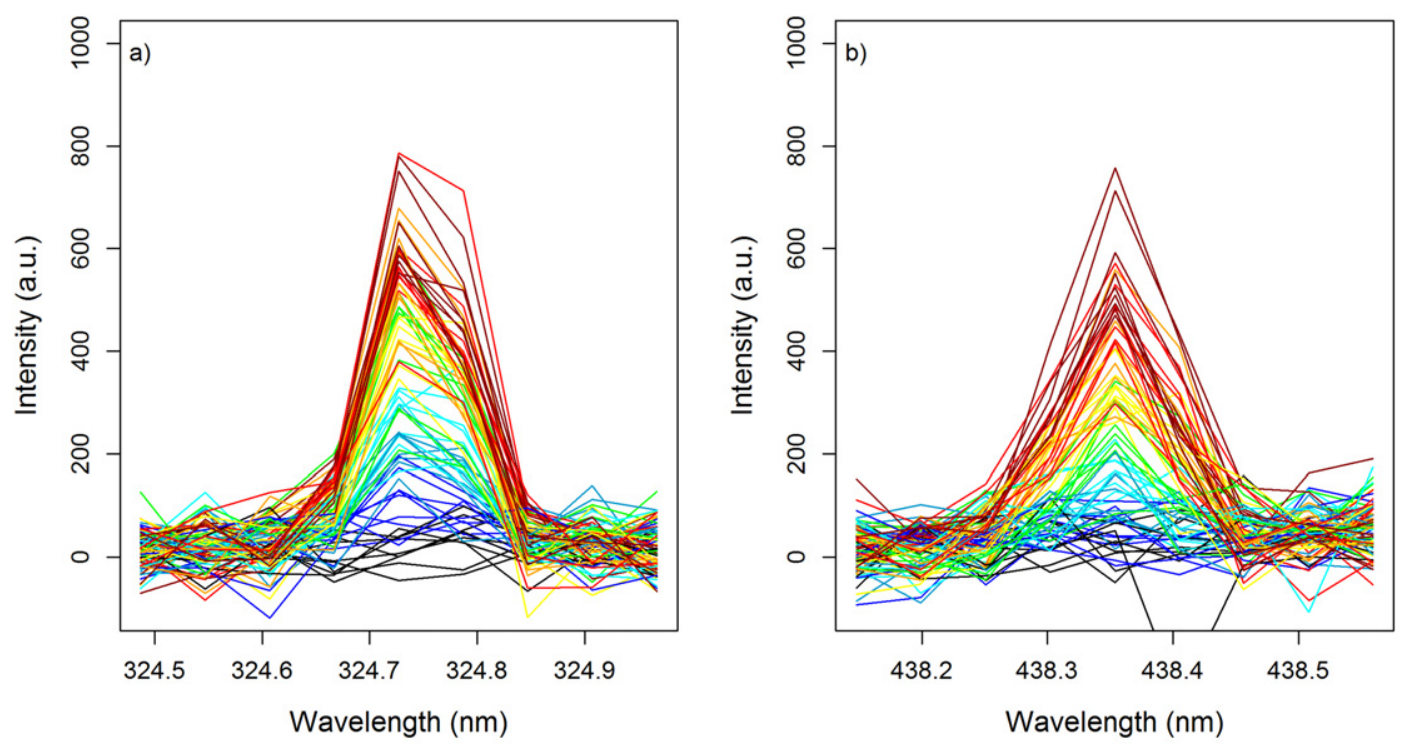

\begin{tabular}{|lllll|}
\hline$\square$ & $\square$ & $20 \mathrm{mg} \mathrm{Cu} / \mathrm{kg}-273 \mathrm{mg} \mathrm{Fe} / \mathrm{kg}$ & $\square 80 \mathrm{mg} \mathrm{Cu} / \mathrm{kg}-1093 \mathrm{mg} \mathrm{Fe} / \mathrm{kg}$ \\
$5 \mathrm{mg} \mathrm{Cu} / \mathrm{kg}-68 \mathrm{mg} \mathrm{Fe} / \mathrm{kg}$ & $\square$ & $40 \mathrm{mg} \mathrm{Cu} / \mathrm{kg}-547 \mathrm{mg} \mathrm{Fe} / \mathrm{kg}$ & $\square 100 \mathrm{mg} \mathrm{Cu} / \mathrm{kg}-1367 \mathrm{mg} \mathrm{Fe} / \mathrm{kg}$ \\
$\square$ & $10 \mathrm{mg} \mathrm{Cu} / \mathrm{kg}-137 \mathrm{mg} \mathrm{Fe} / \mathrm{kg}$ & $\square$ & $60 \mathrm{mg} \mathrm{Cu} / \mathrm{kg}-820 \mathrm{mg} \mathrm{Fe} / \mathrm{kg}$ & $\square 120 \mathrm{mg} \mathrm{Cu} / \mathrm{kg}-1640 \mathrm{mg} \mathrm{Fe} / \mathrm{kg}$ \\
\hline
\end{tabular}

Fig. 2. Closer view of pre-processed and averaged LIBS spectra recorded for all batches at (a) $324.75 \mathrm{~nm}\left(\mathrm{Cu}^{\mathrm{I}}\right)$ and (b) $438.35 \mathrm{~nm}\left(\mathrm{Fe}^{\mathrm{I}}\right)$.

the test sample set. The $R_{p}^{2}$ and RMSEP values generated with the copper model were 0.646 and $24.4 \mathrm{mg} / \mathrm{kg}$, whilst the iron model provided values of 0.797 and $240.9 \mathrm{mg} / \mathrm{kg}$, respectively. Thus, reasonably good simple-linear calibrations were obtained; however, appreciable values of RMSEP indicated poor predictive performance. Low accuracy may be due to variations between set measurements. The LOD vales were 22.03 and $513.5 \mathrm{mg} / \mathrm{kg}$ for the $\mathrm{Cu}$ and the Fe models respectively.

Spectral normalization prior to model building may help compensate for matrix differences [38]. For this purpose, various normalization approaches using different line intensities were tested: C at $247.87 \mathrm{~nm}$, $\mathrm{O}$ at $777.224 \mathrm{~nm}$ and the maximum intensity observed within each spectral range. However, performances of the SLR model built with normalized data were similar to those provided by the models developed with baseline-corrected data. A summary table of the performances is detailed in Table S2. Univariate analysis without internal validation may be subject to repeatability issues [25], Yet, in food applications such as infant formula premixes, sample matrixes are rather complex and heterogeneous hindering internal validation as finding a constant element and knowing its concentration is often not possible $[25,33]$. Therefore, in these cases, univariate analysis should be reserved for obtaining the first understanding of the relationship between analyte emissions and analyte concentration.

\subsubsection{Multi-linear regression (MLR)}

MLR was employed to develop calibration models considering various responses of the target element only. Thus, copper characteristic lines were correlated to the copper variance determined by GFAAS and iron lines to the iron reference values determined by FAAS. The copper model included two $\mathrm{Cu}^{\mathrm{I}}$ lines ( 324.75 and $327.4 \mathrm{~nm}$ ); while the iron model used $\mathrm{Fe}^{\mathrm{I}}(438.36,358.119,373.486,430.79,432.576 \mathrm{~nm})$ and $\mathrm{Fe}^{\mathrm{II}}$ $(259.95 \mathrm{~nm})$. These emission lines correspond to the most prominent emission lines of the elements identified with reference to the NIST database [37] during the exploratory analysis of the spectral data (Section 3.2.). Similarly to SLR, models presented reasonable fits and modest accuracy. For example, the copper model provided an $R^{2}$ of 0.857 and a RMSEP of $24.0 \mathrm{mg} / \mathrm{kg}$. Compared to SLR, MLR performed slightly better in calibration; however no appreciable improvement on the predictive ability was observed in validation. This result was attributed to the fact that the element emission lines selected for building the MLR model were highly correlated.

\subsubsection{Partial least squares regression (PLS)}

PLS models for copper and iron were built by correlating the full LIBS spectra to the reference values. Selection of the optimal number of PLS factors to include in the models was based on the RMSECV since it provides information about the deviation of the model from their reference values [45]. For both models, the RMSECV resulted in a minimum when four factors were included. Performances in calibration were evaluated through the $R^{2}$ and the RMSEC computed with the training set. The estimated values of $R^{2}$ and RMSEC were 0.995 and $2.8 \mathrm{mg} / \mathrm{kg}$ for copper, and 0.995 and $38.7 \mathrm{mg} / \mathrm{kg}$ for iron, indicating high model fitting and accuracy in the frame of calibration. However, when cross-validation was applied, the $R_{C V}^{2}$ and the RMSECV were 0.821 and $16.5 \mathrm{mg} / \mathrm{kg}$ for copper, and 0.819 and $231.5 \mathrm{mg} / \mathrm{kg}$ for iron. The decrease in fit and accuracy was less prominent when the models were validated with the test data set, indicating that the models were not overffited. The copper model yielded an $R_{p}^{2}$ of 0.88 and a RMSEP of $14 \mathrm{mg} / \mathrm{kg}$, while the iron model provided an $R_{p}^{2}$ of 0.89 and a RMSEP of $179 \mathrm{mg} / \mathrm{kg}$. The improvement observed when validating with external data, as opposed to cross-validation, could be due to the presence of outliers within the training set. Roughly, cross-validation LOO conducts an internal validation by consecutively testing the model using a different data point from the training set. Consequently, the presence of outliers within the training set will have an impact on the robustness-assessing parameters. On that account, some recently proposed methodologies for LIBS data pre-processing include discarding of outliers [33].

Further model evaluation was conducted through the loading values which inform about the wavelengths/lines that contributed to each factor. The loadings of the $\mathrm{Cu}$ and Fe models, together with the most probable contributing lines, are displayed in Fig. 3. For both models, the first factor was mainly based on the emission intensities of copper, iron and zinc, demonstrating that the models were principally built on the variation of these elements. The models also accommodated lines from C, Ca, $\mathrm{Na}$ and $\mathrm{K}$, which, despite some possible Na contamination, were mainly matrix constituents. Nitrogen, oxygen and hydrogen also played an important role on the loadings, however their impact is difficult to 

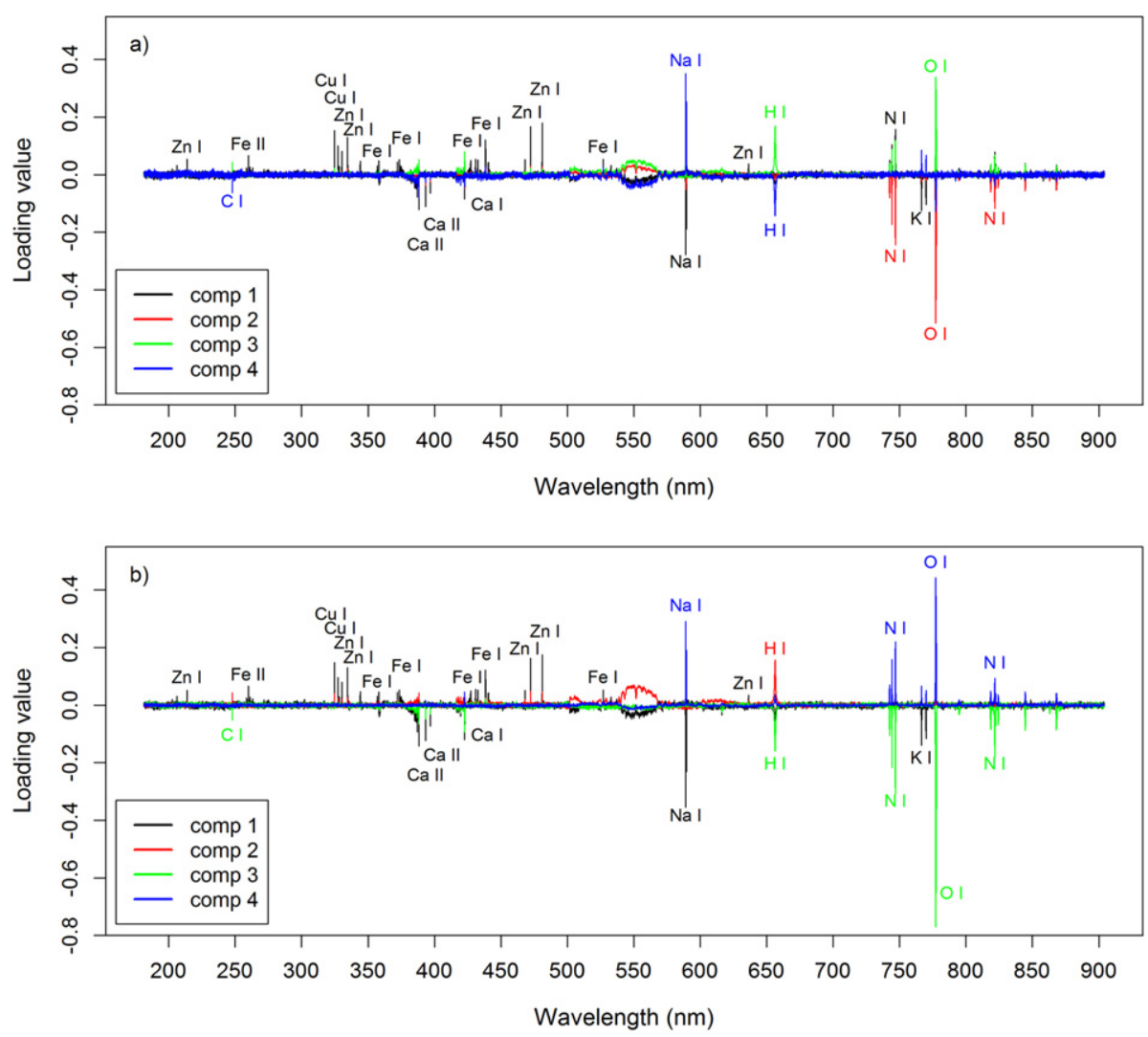

Fig. 3. Loading plots of the PLS models developed for (a) copper and (b) iron predictions.

evaluate due to the involvement of the surrounding air. Attention was also drawn to the fact that both $\mathrm{Cu}$ and Fe calibrations were mostly based on identical analytical lines (mainly Fe, Cu, Zn, C, Ca, Na, K, H, O and $\mathrm{N}$ ) with variations in their loadings. Simultaneous contribution from copper, iron and zinc to both element models was expected since the variation of these elements across the samples was proportional. In applications such as the control of premix addition during the manufacture of infant formula, this phenomenon may be beneficial.
Trace elements in a premix are present in a fix and predetermined ratio; therefore, keeping this proportionally within the PLS model may help alert of a compositional change in the premix. Finally, attention was also drawn to the variance explained by the models. While, for example, the first $\mathrm{Fe}$ factor explained $87 \%$ of the variance within the iron variation, it only accounted for approx. $5 \%$ of variance within the spectral data. This phenomenon could be interpreted as a small part of the whole spectral variation described the changes in iron content and hence, a

Table 2

Summary of model performances conducted for calibration and validation sets.

\begin{tabular}{|c|c|c|c|c|c|c|c|c|c|c|}
\hline \multirow[t]{2}{*}{ Element } & \multicolumn{5}{|c|}{ Calibration } & \multicolumn{2}{|c|}{ Cross Validation } & \multicolumn{3}{|c|}{ Validation } \\
\hline & Data $^{a}$ & Method & Comp & $R^{2}$ & RMSEC $^{\mathrm{b}}$ & $R_{\mathrm{CV}}^{2}$ & RMSECV & $R_{\mathrm{p}}^{2}$ & RMSEP $^{\mathrm{b}}$ & $\mathrm{LOD}^{\mathrm{b}}$ \\
\hline $\mathrm{Cu}$ & Av. & $\operatorname{SLR}^{\mathrm{c}}$ & 1 & 0.851 & 15.0 & - & - & 0.646 & 24.4 & 22.03 \\
\hline $\mathrm{Cu}$ & Av. & $\mathrm{MLR}^{\mathrm{d}}$ & 2 & 0.857 & 14.7 & - & - & 0.658 & 24.0 & 54.7 \\
\hline $\mathrm{Cu}$ & Av. & PLS & 4 & 0.995 & 2.8 & 0.821 & 16.5 & 0.884 & 14.0 & 9.48 \\
\hline $\mathrm{Cu}$ & D1 & PLS & 4 & 0.994 & 2.9 & 0.818 & 16.6 & 0.601 & 25.9 & 10.01 \\
\hline $\mathrm{Cu}$ & D2 & PLS & 4 & 0.994 & 3.1 & 0.773 & 18.6 & 0.836 & 16.6 & 10.8 \\
\hline $\mathrm{Cu}$ & D3 & PLS & 4 & 0.996 & 2.6 & 0.824 & 16.3 & 0.905 & 12.6 & 8.85 \\
\hline $\mathrm{Cu}$ & D4 & PLS & 4 & 0.996 & 2.5 & 0.817 & 16.6 & 0.927 & 11.1 & 8.67 \\
\hline $\mathrm{Cu}$ & D5 & PLS & 4 & 0.998 & 1.9 & 0.829 & 16.1 & 0.934 & 10.6 & 6.57 \\
\hline $\mathrm{Fe}$ & Av. & $\operatorname{SLR}^{\mathrm{e}}$ & 1 & 0.883 & 186.3 & - & - & 0.797 & 240.9 & 513.5 \\
\hline $\mathrm{Fe}$ & Av. & $M_{L}{ }^{f}$ & 6 & 0.905 & 167.9 & - & - & 0.768 & 257.6 & 606.9 \\
\hline $\mathrm{Fe}$ & Av. & PLS & 4 & 0.995 & 38.7 & 0.819 & 231.5 & 0.887 & 179.3 & 133.5 \\
\hline $\mathrm{Fe}$ & D1 & PLS & 4 & 0.996 & 36.7 & 0.826 & 227.4 & 0.622 & 328.5 & 126.4 \\
\hline $\mathrm{Fe}$ & D2 & PLS & 4 & 0.993 & 44.2 & 0.770 & 261.4 & 0.840 & 213.5 & 152.5 \\
\hline $\mathrm{Fe}$ & D3 & PLS & 4 & 0.995 & 36.9 & 0.820 & 231.1 & 0.910 & 160.6 & 127.1 \\
\hline $\mathrm{Fe}$ & D4 & PLS & 4 & 0.996 & 35.6 & 0.816 & 233.5 & 0.918 & 153.0 & 122.5 \\
\hline $\mathrm{Fe}$ & D5 & PLS & 4 & 0.998 & 27.4 & 0.827 & 226.4 & 0.925 & 146.5 & 94.32 \\
\hline
\end{tabular}

a Data refers to the average approach: average of all the spectra recorded per samples (all layers), which is indicated as Av; and averages of all the spectra recorded per depth, which are indicated as D1 (depth 1/surface), D2 (depth 2), etc.

b RMSEC, RMSEP and LOD units are $\mathrm{mg} / \mathrm{kg}$ of $\mathrm{Cu}$ or Fe.

c SLR for Cu used LIBS data at $324.73 \mathrm{~nm}$.

d MLR for Cu used LIBS data at 324.73 and $327.36 \mathrm{~nm}$.

e SLR for Fe used LIBS data at $438.36 \mathrm{~nm}$.

${ }^{\mathrm{f}}$ MLR for Fe used LIBS data at 438.36, 259.95, 358.119, 373.486, 430.79, $432.576 \mathrm{~nm}$. 
major variation was present along the spectral data. The most probable variation was the bulk composition since samples were obtained by adding pure lactose to a commercial premix, causing large matrix variations among the samples.

\subsubsection{Comparison of the calibration approaches}

Three matrix-matched calibration approaches (SLR, MLR and PLS) were tested as feasible LIBS-data processing methodologies. Table 2 summarises the performances in calibration and validation of all the calibration models developed for copper and iron. Best results were obtained when PLS was applied resulting in substantial improvements for all the figures of merit. For instance, the RMSEP of the copper model decreased from $24 \mathrm{mg} / \mathrm{kg}$ (SLR) to $14 \mathrm{mg} / \mathrm{kg}$ (PLS) while the $R^{2}$ rose from 0.851 (SLR) to 0.995 (PLS).

The calibration approaches were further compared via prediction plots. Fig. 4 displays the copper and iron values predicted with each of the calibration approaches versus the measured values determined by AAS. In accordance with the figures of merit, SLR (Fig. 4(a)) and MLR (Fig. 4(b)) yielded modest models with noticeable lack of fit and accuracy, especially in the frame of validation. In contrast, PLS (Fig. 4(c)) showed excellent fitting and good accuracy. In general, less accuracy was observed when targeting samples of $\mathrm{Cu}$ and Fe levels close to the limits of the concentration range. This effect was probably due to a substantial change in matrix, including composition and particle features [46], as the samples of lower and upper concentration limits were pure lactose and premix, respectively. Contrary, when targeting premix-lactose blends, predictions were notably more accurate, especially by means of PLS. Overall results corroborated that chemometric methods such as PLS, in which several or the entire spectral information is considered for calibration building, reduces matrix effects, improving the accuracy of the quantifications $[19,20,25]$.

\subsection{Surface versus inner-sample measurements}

LIBS can be employed to penetrate through the sample by repetitively firing the laser at the same spot. This feature may be useful to provide information about the bulk composition as well as to clean the surface of the sample and expose underlying material before element analysis. In this section, in-depth recording was investigated in terms of effect on the spectral quality and also as a mechanism to avoid possible surface contaminants. To this end, each depth was assessed individually.

As for previous PLS models developed per sample, the spectral data-here arranged by depth-was correlated to the reference values, providing 5 extra PLS models per element. The resulting figures of merit are detailed in Table 2, together with the values of the models developed with the average spectra of all the sample layers. In contrast to the all-layers models, the models developed with the first-layer (surface) data, indicated in the table as D1, showed a poor performance in the frame of validation (RMSEP values of $25.9 \mathrm{mg} / \mathrm{kg} \mathrm{Cu}$ and $228.5 \mathrm{mg} / \mathrm{kg} \mathrm{Fe}$ ). However, model performances improved as the measuring depth increased, providing better results than the all-layers model. This effect is also visible in Fig. 4(d), which displays Cu predicted
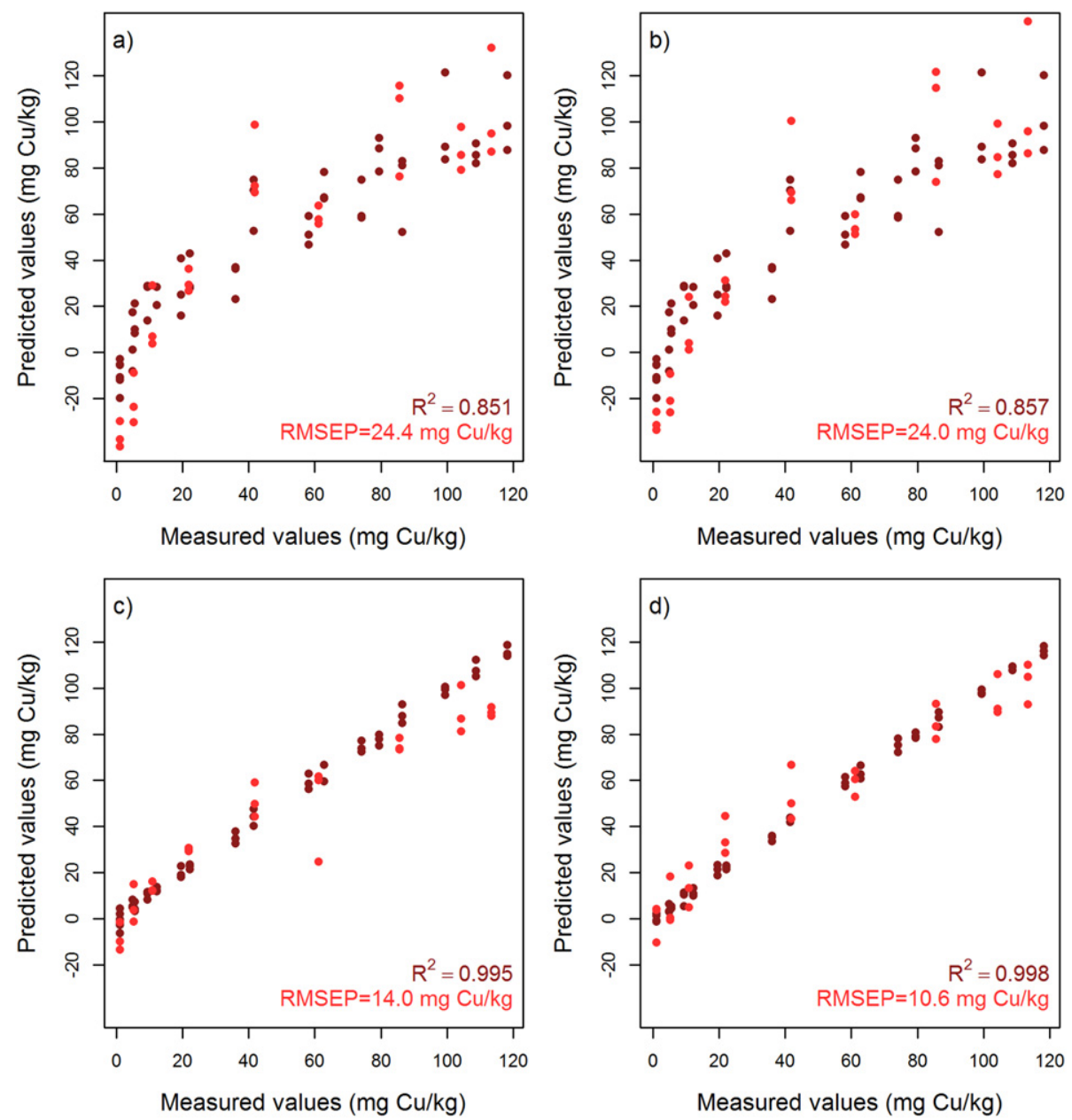

- Cu calibration - Cu prediction

Fig. 4. Predicted vs measured plots for copper obtained with (a) SLR, (b) MLR, (c) PLS and (d) PLS at depth 5. 

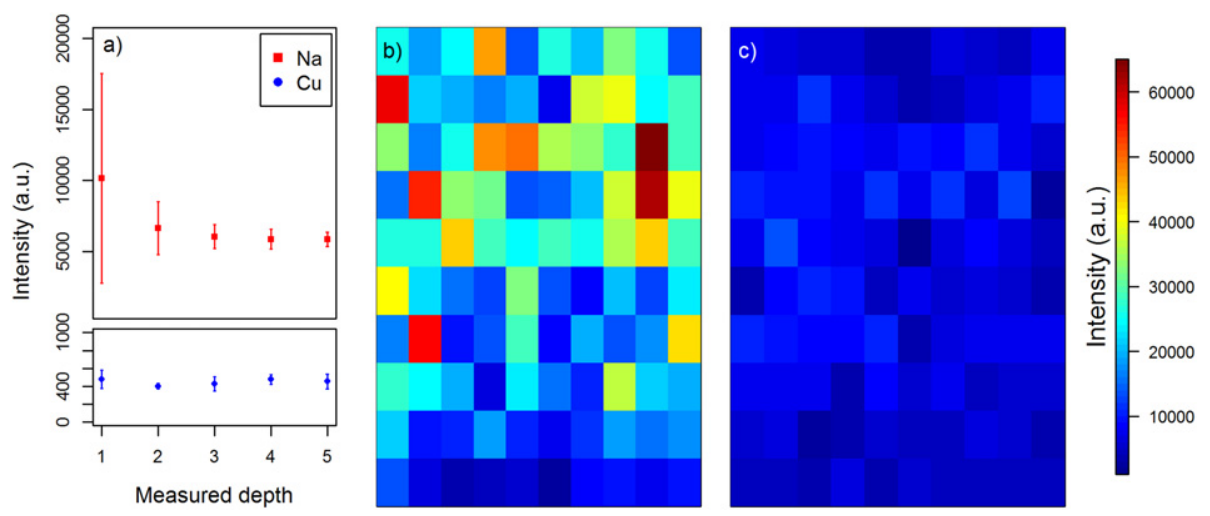

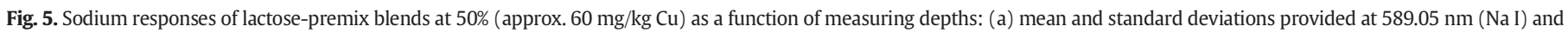
comparison with $\mathrm{Cu}^{\mathrm{I}}$ at $324.75 \mathrm{~nm}$, (b) Sodium map obtained at depth 1 (surface) and (c) Sodium map obtained at depth 5 (deepest distance studied).

values obtained with the depth-5 model versus reference values. Poorer predictive ability when analysing surface data may indicate presence of external elements, probably introduced due to surface contamination.

In order to disclose possible surface contamination, the presence of sodium through the 5 layers was investigated. Sodium is easily detected by the LIBS system, which means that slight variations of its levels may have a considerable impact on the LIBS signal and hence on the chemical analysis. Fig. 5 displays some of the sodium responses obtained for the premix samples at 50\% (approx. $60 \mathrm{mg} / \mathrm{kg} \mathrm{Cu}$ ). The first sub-plot, Fig. 5(a), shows the intensity mean and deviation at the Na line $589.05 \mathrm{~nm}$ as a function of the measured layer. Both statistics tended to decrease with the measuring depth. Yet, from the surface (depth 1) to depth 2, the drop in both statistics is remarkable. For comparison purposes, the variance of copper across the measured depths was also displayed in Fig. 5(a). Unlike sodium, copper variations did not show a clear pattern associated with depth. Fig. 5(b) and (c) display sodium chemical maps of the same pellet at depth 1 and depth 5 , respectively. As expected, the image provided at the surface (Fig. 5(b)) revealed some spots with high Na intensity values as well as large Na variation across the scanned area. This result indicated that some surface locations contained high $\mathrm{Na}$ concentrations and also that Na was not homogeneously distributed. Conversely, as evident in Fig. 5(c), the image of the inner measurement disclosed modest intensity values and variations. Thus, Na detected at the surface may not only be from the sample matrix but also from an external source. Then, models built with surface data may include Na variation not matrix related resulting in less accuracy. These results leads us to conclude that performing conditioning shots prior to recording LIBS spectra may help avoid possible surface contamination issues.

\section{Conclusions}

LIBS in combination with chemometric techniques including PLS regression was successfully applied for copper and iron quantifications in infant formula premixes. The study provided a comparison between three matrix-matched approaches: simple linear regression (SLR), multi-linear regression (MLR) and partial least squares regression (PLS). While SLR and MLR demonstrated to be appropriate for determining exploratory relationships between the analyte and the spectral information, PLS proved its capability as a quantitative approach of LIBS data. Good performances of the PLS approach have been demonstrated via figures of merit (e.g. $R^{2}$ of 0.995 and RMSEP of $14 \mathrm{mg} / \mathrm{kg}$ $\mathrm{Cu})$, prediction plots and loading values. The latter revealed that main contributing emission lines were related to premix trace elements, namely $\mathrm{Cu}, \mathrm{Fe}$ and $\mathrm{Zn}$, as well as to the matrix and the surrounding air. Therefore, the analyte-matrix and analyte-environment combinations have an active role in the LIBS spectra. On that account, better predictive ability may be obtained by including both related and non- directly related element emission lines into the model. PLS allows such consideration and, in this study, has demonstrated its overall benefits. Furthermore, LIBS was used to bore through the sample in order to explore whether better spectral quality could be obtained at deeper sample layers. Results indicated that surface measurements should be avoided, possibly due to surface contaminations. To conclude, this work served to corroborate that chemometric approaches/multivariate analysis such as PLS help deal with matrix effects leading to more accurate quantifications. Therefore, LIBS followed by PLS holds significant potential as a rapid quantitative tool for trace element analysis of infant formula premixes during manufacture.

Prior to data recording, laser radiation can be used to clean the surface of the sample and expose underlying material before element analysis. This feature may be especially useful when absence of surface contaminants cannot be guaranteed. Benefits of analysing inner layers were investigated using sodium as example. Sodium is highly detected by LIBS, consequently; it may have a considerable impact on subsequent chemical analyses.

\section{Acknowledgements}

The authors would like to acknowledge funding from the Food Institutional Research Measure, administered by the Department of Agriculture, Food and the Marine, Ireland (Grant agreement: 14/F/866).

\section{Appendix A. Supplementary data}

Supplementary data to this article can be found online at http://dx. doi.org/10.1016/j.sab.2017.06.014.

\section{References}

[1] D.H. Montagne, P. Van Dael, M. Skanderby, W. Hugelshofer, Infant formulae - powders and liquids, Dairy Powders and Concentrated Products, Wiley-Blackwell 2009, pp. 294-331.

[2] M. Guo, S. Ahmad, 6 - formulation guidelines for infant formula, in: M. Guo (Ed.), Human Milk Biochemistry and Infant Formula Manufacturing Technology, Woodhead Publishing 2014, pp. 141-171.

[3] D.A. Cook, Nutrient levels in infant formulas: technical considerations, The Journal of Nutrition 119 (1989) 1773-1777 (discussion 1777-1778)

[4] W.C. MacLean Jr., P. Van Dael, R. Clemens, J. Davies, E. Underwood, L. O'Risky, D. Rooney, J. Schrijver, Upper levels of nutrients in infant formulas: comparison of analytical data with the revised Codex infant formula standard, Journal of Food Composition and Analysis 23 (2010) 44-53, http://dx.doi.org/10.1016/j.jfca.2009.07.008.

[5] Food and Drug Administration (FDA), 21CFR106.6 Part 106 - infant formula quality control procedures, http://www.accessdata.fda.gov/scripts/cdrh/cfdocs/cfcfr/ CFRSearch.cfm?CFRPart=106 2016 accessed 20/04/2017.

[6] Comission of the European Communities, Commission Directive 2006/141/EC of 22 December 2006 on infant formulae and follow-on formulae and amending Directive 1999/21/EC Text with EEA relevance Official Journal of the European Union, http:// eur-lex.europa.eu/legal-content/EN/ALL/?uri=CELEX\%3A32006L0141 2006 accessed 20.04.17. 
[7] L. Perring, D. Andrey, M. Basic-Dvorzak, D. Hammer, Rapid quantification of iron, copper and zinc in food premixes using energy dispersive X-ray fluorescence, Journal of Food Composition and Analysis 18 (2005) 655-663, http://dx.doi.org/10. 1016/j.jfca.2004.06.011.

[8] Y.J. Jiang, 11 - infant formula product regulation, in: M. Guo (Ed.), Human Milk Biochemistry and Infant Formula Manufacturing Technology, Woodhead Publishing 2014, pp. 273-310.

[9] Codex Alimentarius Commission, CODEX STAN 72 - 1981: standard for infant formula and formulas for especial medical purposes intended for infants, www.fao. org/input/download/standards/288/CXS_072e_2015.pdf 1981 accessed 20.04.17.

[10] Codex Alimentarius Commission, Report of the 30th session of the codex committee on nutrition and foods for special dietary uses, www.fao.org/input/download/report/710/al32_26e.pdf 2009 accessed 20.04.17.

[11] D.A. Cremers, L.J. Radziemski, Introduction, Handbook of Laser-Induced Breakdown Spectroscopy, John Wiley \& Sons Ltd 2013, pp. 1-27.

[12] E.C. Ferreira, E.A. Menezes, W.O. Matos, D.M.B.P. Milori, A.R.A. Nogueira, L. MartinNeto, Determination of Ca in breakfast cereals by laser induced breakdown spectroscopy, Food Control 21 (2010) 1327-1330, http://dx.doi.org/10.1016/j.foodcont. 2010.04.004.

[13] F.J. Fortes, J. Moros, P. Lucena, L.M. Cabalín, J.J. Laserna, Laser-induced breakdown spectroscopy, Analytical Chemistry 85 (2013) 640-669, http://dx.doi.org/10.1021/ ac303220r.

[14] D.A. Cremers, L.J. Radziemski, LIBS analytical figures of merit and calibration, Handbook of Laser-Induced Breakdown Spectroscopy, John Wiley \& Sons Ltd 2013, pp. 123-150.

[15] F. Anabitarte, A. Cobo, J.M. Lopez-Higuera, Laser-induced breakdown spectroscopy: fundamentals, applications, and challenges, ISRN Spectroscopy 2012 (2012) 12, http://dx.doi.org/10.5402/2012/285240.

[16] A.O. Mehder, Y.B. Habibullah, M.A. Gondal, U. Baig, Qualitative and quantitative spectro-chemical analysis of dates using UV-pulsed laser induced breakdown spectroscopy and inductively coupled plasma mass spectrometry, Talanta 155 (2016) 124-132, http://dx.doi.org/10.1016/j.talanta.2016.04.036.

[17] N. Gilon, J. El-Haddad, A. Stankova, W. Lei, Q. Ma, V. Motto-Ros, J. Yu, A matrix effect and accuracy evaluation for the determination of elements in milk powder LIBS and laser ablation/ICP-OES spectrometry, Analytical and Bioanalytical Chemistry 401 (2011) 2681-2689, http://dx.doi.org/10.1007/s00216-011-5079-z.

[18] M. Markiewicz-Keszycka, X. Cama-Moncunill, M.P. Casado-Gavalda, Y. Dixit, R. Cama-Moncunill, P.J. Cullen, C. Sullivan, Laser-induced breakdown spectroscopy (LIBS) for food analysis: a review, Trends in Food Science and Technology http:// dx.doi.org/10.1016/j.tifs.2017.05.005.

[19] J. El Haddad, L. Canioni, B. Bousquet, Good practices in LIBS analysis: review and advices, Spectrochimica Acta Part B: Atomic Spectroscopy 101 (2014) 171-182, http:// dx.doi.org/10.1016/j.sab.2014.08.039.

[20] G. Galbács, A critical review of recent progress in analytical laser-induced breakdown spectroscopy, Analytical and Bioanalytical Chemistry 407 (2015) 7537-7562, http://dx.doi.org/10.1007/s00216-015-8855-3.

[21] M.-B.S. Andersen, J. Frydenvang, P. Henckel, Å. Rinnan, The potential of laser-induced breakdown spectroscopy for industrial at-line monitoring of calcium content in comminuted poultry meat, Food Control 64 (2016) 226-233, http://dx.doi.org/ 10.1016/j.foodcont.2016.01.001.

[22] Z. Abdel-Salam, J. Al Sharnoubi, M.A. Harith, Qualitative evaluation of maternal milk and commercial infant formulas via LIBS, Talanta 115 (2013) 422-426, http://dx.doi. org/10.1016/j.talanta.2013.06.003.

[23] I.B. Gornushkin, U. Panne, Radiative models of laser-induced plasma and pumpprobe diagnostics relevant to laser-induced breakdown spectroscopy, Spectrochimica Acta Part B: Atomic Spectroscopy 65 (2010) 345-359, http://dx. doi.org/10.1016/j.sab.2010.03.021.

[24] E. Tognoni, G. Cristoforetti, [INVITED] signal and noise in laser induced breakdown spectroscopy: an introductory review, Optics and Laser Technology 79 (2016) 164-172, http://dx.doi.org/10.1016/j.optlastec.2015.12.010.

[25] J. Peng, F. Liu, F. Zhou, K. Song, C. Zhang, L. Ye, Y. He, Challenging applications for multi-element analysis by laser-induced breakdown spectroscopy in agriculture: a review, TrAC Trends in Analytical Chemistry 85 (Part C) (2016) 260-272, http:// dx.doi.org/10.1016/j.trac.2016.08.015.

[26] W.Q. Lei, J. El Haddad, V. Motto-Ros, N. Gilon-Delepine, A. Stankova, Q.L. Ma, X.S. Bai, L.J. Zheng, H.P. Zeng, J. Yu, Comparative measurements of mineral elements in milk powders with laser-induced breakdown spectroscopy and inductively coupled plasma atomic emission spectroscopy, Analytical and Bioanalytical Chemistry 400 (2011) 3303-3313, http://dx.doi.org/10.1007/s00216-011-4813-x.

[27] E. Tognoni, G. Cristoforetti, S. Legnaioli, V. Palleschi, Calibration-free laser-induced breakdown spectroscopy: state of the art, Spectrochimica Acta Part B: Atomic Spectroscopy 65 (2010) 1-14, http://dx.doi.org/10.1016/j.sab.2009.11.006.
[28] D.A. Cremers, L.J. Radziemski, Quantitative LIBS analysis, Handbook of Laser-Induced Breakdown Spectroscopy, John Wiley \& Sons Ltd 2013, pp. 185-222.

[29] G. Bilge, B. Sezer, K.E. Eseller, H. Berberoglu, A. Topcu, I.H. Boyaci, Determination of whey adulteration in milk powder by using laser induced breakdown spectroscopy, Food Chemistry 212 (2016) 183-188, http://dx.doi.org/10.1016/j.foodchem.2016. 05.169 .

[30] A. dos Santos Augusto, P.L. Barsanelli, F.M.V. Pereira, E.R. Pereira-Filho, Calibration strategies for the direct determination of $\mathrm{Ca}, \mathrm{K}$, and $\mathrm{Mg}$ in commercial samples of powdered milk and solid dietary supplements using laser-induced breakdown spectroscopy (LIBS), Food Research International (2017) http://dx.doi.org/10.1016/j. foodres.2017.01.027.

[31] X. Cama-Moncunill, M. Markiewicz-Keszycka, Y. Dixit, R. Cama-Moncunill, M.P. Casado-Gavalda, P.J. Cullen, C. Sullivan, Feasibility of laser-induced breakdown spectroscopy (LIBS) as an at-line validation tool for calcium determination in infant formula, Food Control 78 (2017) 304-310, http://dx.doi.org/10.1016/j.foodcont.2017. 03.005 .

[32] J.L. Gottfried, D.A. Cremers, L.J. Radziemski, Chemometric analysis in LIBS, Handbook of Laser-Induced Breakdown Spectroscopy, John Wiley \& Sons Ltd 2013, pp. 223-255.

[33] P. Sobron, A. Wang, F. Sobron, Extraction of compositional and hydration information of sulfates from laser-induced plasma spectra recorded under Mars atmospheric conditions - implications for ChemCam investigations on curiosity rover Spectrochimica Acta Part B: Atomic Spectroscopy 68 (2012) 1-16, http://dx.doi. org/10.1016/j.sab.2012.01.002.

[34] M.D. Dyar, S. Giguere, C.J. Carey, T. Boucher, Comparison of baseline removal methods for laser-induced breakdown spectroscopy of geological samples, Spectrochimica Acta Part B: Atomic Spectroscopy 126 (2016) 53-64, http://dx.doi. org/10.1016/j.sab.2016.10.018.

[35] K.H. Liland, B.R.-H. Mevik, Baseline: Baseline Correction of Spectra, R package version, 1.2-0, http://CRAN.R-project.org/package=baseline 2015.

[36] G. James, D. Witten, T. Hastie, R. Tibshirani, Linear regression, An Introduction to Statistical Learning: With Applications in R, Springer New York, New York, NY 2013, pp. 59-126.

[37] A. Kramida, Y. Ralchenko, J. Reader, N.A. Team, NIST Atomic Spectra Database (Ver 5.4), [Online], National Institute of Standards and Technology, Gaithersburg, MD http://physics.nist.gov/PhysRefData/Handbook/Tables/findinglist.htm 2016 accessed 21.04.17.

[38] J.P. Castro, E.R. Pereira-Filho, Twelve different types of data normalization for the proposition of classification, univariate and multivariate regression models for the direct analyses of alloys by laser-induced breakdown spectroscopy (LIBS), Journal of Analytical Atomic Spectrometry 31 (2016) 2005-2014, http://dx.doi.org/10. 1039/C6JA00224B.

[39] J.N. Miller, J.C. Miller, Statistics and Chemometrics for Analytical Chemistry, Prentice Hall/Pearson, 2010.

[40] Y. Dixit, M.P. Casado-Gavalda, R. Cama-Moncunill, M. Markiewicz-Keszycka, P. Cruise, F. Jacoby, P.J. Cullen, C. Sullivan, NIR spectrophotometry with integrated beam splitter as a process analytical technology for meat composition analysis, Analytical Methods (2016)http://dx.doi.org/10.1039/C6AY00816J.

[41] N. Kumar, A. Bansal, G.S. Sarma, R.K. Rawal, Chemometrics tools used in analytical chemistry: an overview, Talanta 123 (2014) 186-199, http://dx.doi.org/10.1016/j. talanta.2014.02.003.

[42] F. Allegrini, A.C. Olivieri, IUPAC-consistent approach to the limit of detection in partial least-squares calibration, Analytical Chemistry 86 (2014) 7858-7866, http://dx. doi.org/10.1021/ac501786u.

[43] M.P. Casado-Gavalda, Y. Dixit, D. Geulen, R. Cama-Moncunill, X. Cama-Moncunill, M Markiewicz-Keszycka, P.J. Cullen, C. Sullivan, Quantification of copper content with laser induced breakdown spectroscopy as a potential indicator of offal adulteration in beef, Talanta 169 (2017) 123-129, http://dx.doi.org/10.1016/j.talanta.2017.03.071.

[44] A.K. Pathak, R. Kumar, V.K. Singh, R. Agrawal, S. Rai, A.K. Rai, Assessment of LIBS for spectrochemical analysis: a review, Applied Spectroscopy Reviews 47 (2012) 14-40, http://dx.doi.org/10.1080/05704928.2011.622327.

[45] R. Cama-Moncunill, M. Markiewicz-Keszycka, Y. Dixit, X. Cama-Moncunill, M.P. Casado-Gavalda, P.J. Cullen, C. Sullivan, Multipoint NIR spectroscopy for gross composition analysis of powdered infant formula under various motion conditions, Talanta 154 (2016) 423-430, http://dx.doi.org/10.1016/j.talanta.2016.03.084.

[46] Y. Dixit, M.P. Casado-Gavalda, R. Cama-Moncunill, M. Markiewicz-Keszycka, X. Cama-Moncunill, P.J. Cullen, C. Sullivan, Quantification of rubidium as a trace element in beef using laser induced breakdown spectroscopy, Meat Science 130 (2017) 47-49, http://dx.doi.org/10.1016/j.meatsci.2017.03.013. 